\title{
¿Y después de la Cirugía, qué?
}

\author{
And after Surgery, what?
}

Ricardo Espinoza González ${ }^{1}$

La formación de un cirujano toma no menos de 12 años, y con frecuencia hasta 15 años. Concluida esa etapa inicial de formación, el cirujano se integra al campo laboral ganando experiencia y va madurando hacia la mitad de su carrera, cuando lleva al menos unos 10 años de práctica quirúrgica. A esas alturas esa persona ya ha alcanzado la cuarta década de la vida. Pero, ¿por cuánto tiempo ejercerá la cirugía? Con el aumento de la longevidad se ha ido observando que los cirujanos se mantienen activos hasta edades cada vez mayores. Si en la década de los 80 la edad de retiro se situaba en torno a los 60 años, para los 90 ya se había elevado hasta los 63 años de edad. En la actualidad, los cirujanos planifican mantenerse operando hasta los 65 años y con actividad profesional hasta los 70 . Indudablemente que esto es variable de persona a persona y también depende de la legislación de los países. Sin embargo, la tendencia observada es aumentar el período de actividad profesional y responde a varias razones: las principales son la satisfacción por lo que se hace y el sentido de identidad que da la misma profesión, específicamente la cirugía; también está la camaradería quirúrgica y, en casi la mitad de los casos, el cirujano se mantiene operando por razones relacionadas a sus finanzas personales.

Con todo, después de los 65 años, puede hacerse evidente un trastorno cognitivo que haga aconsejable no seguir practicando la cirugía. Será preferible dejar la cirugía, a que la cirugía lo deje a uno. Pues bien, ya sea por causa de un deterioro cognitivo u otras, como puede ser el burnout, un asunto de litigio, o sencillamente querer desarrollar otras cosas, hay que enfrentar en algún momento el retiro. El retiro significa una transición compleja para cualquier profesional. Por tanto, el retiro debe abordarse con realismo e idealmente de manera planificada.

Quienes han estudiado estas etapas de transición han identificado varios elementos de importancia para hacerla adecuadamente, descubriendo territo- rios y áreas de desarrollo insospechadas, y nunca planteados antes. Se trata de reconocer que, en la vida personal, y profesional también, se dan ciclos, y es tremendamente útil darse cuenta cuándo se está acabando uno y se está abriendo otro. La persona, mientras antes tome una decisión, mejor será, para que esta transición se desarrolle de forma incluso atractiva, sin temor a dejar ni un puesto, ni un salario. Para ello se debe conocer uno mismo: ¿qué es lo que me hace disfrutar?, ¿estoy dispuesto a arriesgar en seguridad?, ¿qué habilidades aprendidas pretendo seguir empleando? Como bien lo expresa Avivah Wittenberg-Cox: "ni la fama ni la fortuna pueden alimentar el alma insatisfecha". Por tanto, la transición se debe planificar. Habrá que escuchar lo externo, ¿qué de lo realizado me ha traído más entusiasmo?, ¿de qué actividades he obtenido la mejor apreciación?

La planificación requiere que nos dejemos aconsejar, que seamos realistas, que tengamos un plan de financiamiento $\mathrm{y}$, muy importantemente, que tengamos el apoyo de una esposa o una pareja. Los cirujanos somos personas con alta capacidad de tomar decisiones, incluso con información incompleta. Somos capaces de saber vivir con el estrés y en situaciones altamente demandantes. Sabemos comunicarnos con variadas personas y siempre hemos trabajado en equipo. Debemos haber desarrollado compasión por las miserias de los demás, o al menos empatía. Pues bien, con todos esos atributos, se nos abre un sinnúmero de posibilidades: en educación, en el voluntariado, en la asesoría o formación de una compañía de la industria asociada a la salud, en comisiones gubernamentales de acreditación y certificación, en la investigación. Por cierto, en el estudio de arte, música, historia, lenguas, entre muchas otras opciones.

En fin, frente a la transición debemos ser capaces de descubrir espacios inexplorados, con realismo, de modo planificado y optimista, viendo siempre oportunidades de ser más felices, apuntando al bienestar físico, emocional y espiritual de cada uno.
${ }^{1}$ Facultad de Medicina y Clínica Universidad de los Andes. Santiago, Chile.

Correspondencia a: respinoza@clinicauandes.cl 


\section{EDITORIAL}

\section{Bibliografía}

1. Jonasson O, Kwakwa F. Retirement Age and the Work Force in General Surgery. Ann Surg. 1996;224:574-82.

2. Poushay HM, Kagedan DJ, Hallet J,
Conn LG, Beyfuss K, Nadler A, et al. Why Do General Surgeons Decide to Retire?: A poulation-level Survey.Ann Surg. 2018;267:e4-e5. doi: 10.1097/
SLA.0000000000002467.

3. Avivah Wittenberg-Cox: Learn to Get Better at Transitions. Harvard Business Review, 2018. 